\title{
Olfactory receptor Olfr78 (prostate-specific G protein-coupled receptor PSGR) expression in arterioles supplying skeletal and cardiac muscles and in arterioles feeding some murine organs
}

\author{
Petra Mermer ${ }^{1} \cdot$ Jörg Strotmann ${ }^{2} \cdot$ Wolfgang Kummer ${ }^{1} \cdot$ Renate Paddenberg $^{1}$ (D)
}

Accepted: 3 September 2021 / Published online: 20 September 2021

(c) The Author(s) 2021

\begin{abstract}
The olfactory receptor Olfr78 (prostate-specific G protein-coupled receptor PSGR) is a member of the G protein-coupled receptor family mediating olfactory chemosensation, but it is additionally expressed in other tissues. Olfr78 expressed in kidney participates in blood pressure regulation, and in prostate it plays a role in the development of cancer. We here screened many organs/tissues of transgenic mice co-expressing $\beta$-galactosidase with Olfr78. X-gal-positive cells were detectable in smooth muscle cells of numerous arterioles of striated muscles (heart ventricles and skeletal muscles of various embryological origin). In addition, in most organs where we found expression of Olfr78 mRNA, X-gal staining was restricted to smooth muscle cells of small blood vessels. The dominant expression of Olfr78 in arteriolar smooth muscle cells supports the concept of an important role in blood pressure regulation and suggests a participation in the fine tuning of blood supply especially of striated muscles. This should be considered when targeting Olfr78 in other contexts such as prostate cancer.
\end{abstract}

Keywords Arterioles · Mouse · Olfactory receptor Olfr78 · Prostate-specific G protein-coupled receptor PSGR · Striated muscles $\cdot$ X-gal staining

\section{Introduction}

G protein-coupled receptors (GPCRs) are important for many functions in the human body including signalling in vision and smell, regulation of mood and behaviour, the nervous and the immune system, inflammation, and many other biological processes. Therefore, it is not surprising that GPCRs represent the largest family of protein targets for approved drugs (Sriram and Insel 2018; Heifetz et al. 2015).

Olfactory receptor (OR) Olfr78 is a member of the GPCR family and mediates olfactory chemosensation in the nose. Unfortunately, several different names are used for Olfr78, depending on the species analysed and the organs investigated. Olfr78 [= official name according to the Mouse

Renate Paddenberg

Renate.Paddenberg@ anatomie.med.uni-giessen.de

1 Institute of Anatomy and Cell Biology, Excellence Cluster Cardio-Pulmonary Institute, German Center for Lung Research, Justus Liebig University, Aulweg 123, 35385 Giessen, Germany

2 Institute of Physiology, University of Hohenheim, 70599 Stuttgart, Germany
Genome Informatics (MGI); aliases: 4633402A21Rik, MOL2.3, MOR18-2, Or51e2, PSGR, RA1c] was first discovered to be highly expressed in human prostate and thus initially named prostate-specific $\mathrm{G}$ protein coupled receptor (PSGR). It was later found that human PSGR belongs to the OR superfamily; hence, it was renamed as OR family 51 subfamily E member 2 (OR51E2) [= official name according to the HUGO Gene Nomenclature Committee (HGNC); aliases: PSGR, HPRAJ, OR52A2, OR51E3P]. However, in the community working on prostate, PSGR is still a commonly used term for murine models and PSGR or OR51E2 for human studies. In rat, Olfr78 is called Olr59 [according to the Rat Genome Nomenclature Committee (RGNC); aliases: Olfr78, Or51e2, RA1c].

Particularly through transcriptomic research, Olfr 78 was found to be expressed not only in the olfactory epithelium but also in many other tissues including kidney and prostate. Pluznick et al. (2013) used a mouse strain in which the gene encoding Olfr78 was replaced by $\beta$-galactosidase and found expression of Olfr78 in smooth muscle cells of small resistance vessels and in juxtaglomerular arterioles of the kidney. They identified the short chain fatty acids (SCFA) acetate and propionate as ligands 
of Olfr78 and demonstrated the participation of Olfr78 in blood pressure regulation. For this reason, the receptor and its ligands may be relevant in the pathogenesis of hypertension and development of new drugs for treatment of this disease.

OR51E2 is expressed in prostate epithelial cells, and expression is significantly increased in prostate intraepithelial neoplasia and prostate cancer relative to healthy tissue and benign prostatic hyperplasia (Weng et al. 2005). Although the exact function of the receptor in prostate cancer has not yet been clarified, these data indicate the importance of OR51E2 in the pathogenesis of prostate cancer and OR51E2, and its ligand may be a new target to better combat prostate cancer.

Against the background of the potential importance of Olfr78 for the development and treatment of serious diseases, the aim of our work was to examine the expression of Olfr78 in mouse. Identification of Olfr78 protein-expressing cells may point to further functions of the receptor. We performed RT-PCR to analyse Olfr78 mRNA expression and used reporter mice co-expressing $\beta$-galactosidase and Olfr78 to detect Olfr78-expressing cells in several murine organs and tissues.

\section{Materials and methods}

\section{Animals}

In this study, we used C57B16 wildtype (WT) mice $(n=3)$ and the transgenic mouse line MOL2.3-IGITL (designation in our animal facility and in the permission: CD1;129Olfr78 ${ }^{\text {tmljgst }}(n=17)$. In this mouse line, green fluorescent protein (GFP) and tau/ $\beta$-galactosidase are co-expressed with Olfr78 (Conzelmann et al. 2000). Mice of both sexes aged between 2 and 11 months were used.

Mice were housed in GM 500 individually ventilated cages (Tecniplast Deutschland GmbH, Hohenpeißenberg, Germany) under specific pathogen-free conditions at $23{ }^{\circ} \mathrm{C}$ temperature and $50 \%$ humidity. Mice had free access to water and standard diet pellets (Altromin Spezialfutter GmbH \& Co. KG, Lage, Germany). They were kept in $14 \mathrm{~h}$ light/10 h dark cycle conditions. Each cage was equipped with a mouse house and rodent wood as environmental enrichment. The cage-change interval was about 7 days.

All experiments were performed according to the national and international guidelines and with approval of local authorities (Animal Welfare Officer at the University of Giessen) and of the Federal Authorities for Animal Research of the Regierungspräsidium Giessen (Hessen, Germany), registration number (no. 614_M).

\section{Reverse transcription-PCR (RT-PCR)}

Total RNA from organs/tissues [carotid bifurcation together with the superior cervical ganglion and attached carotid body, olfactory mucosa, tip of the tongue, outer ocular muscles, cheek muscles, thigh muscles, diaphragm, intercostal muscles, heart, trachea, lung, oesophagus, stomach, small intestine, colon, liver, gallbladder, kidney, urinary bladder, adrenal gland, thymus, spleen, lymph node, testis, epididymis, prostate, seminal vesicle, ovary, oviduct, uterus, vagina, femoral artery, vein and nerve, adipose tissue, auricle of the ear, and DRGs (dorsal root ganglia); $n=1-5$ for each organ/tissue; exact numbers are given in Table 1] was extracted using RNeasy Micro Kit (Qiagen, Hilden, Germany) according to the manufacturer's protocol. For removal of genomic DNA contamination, up to $1 \mu \mathrm{g}$ RNA in $8 \mu \mathrm{l}$ water was incubated with $1 \mu 110 \times$ DNase reaction buffer and $1 \mu \mathrm{l}$ DNase (1 U/ $\mu \mathrm{l}$; Invitrogen, Darmstadt, Germany) for $15 \mathrm{~min}$ at $25^{\circ} \mathrm{C}$. Then, $1 \mu$ l ethylenediaminetetraacetic acid $(25 \mathrm{mM})$ was added to each sample. After $10 \mathrm{~min}$ incubation at $65{ }^{\circ} \mathrm{C}$, samples were rapidly chilled on ice and $9 \mu \mathrm{l}$ reaction mixture containing $1 \mu \mathrm{l}$ oligo-dT $(50 \mu \mathrm{M})$, $1 \mu \mathrm{l}$ dNTPs (10 mM), $1 \mu \mathrm{l}$ Superscript RNase H- Reverse Transcriptase (RT; $200 \mathrm{U} / \mu \mathrm{l}), 4 \mu \mathrm{l} 5 \times$ first-strand buffer, and $2 \mu \mathrm{l}$ dithiothreitol $(0.1 \mathrm{M}$; all reagents were purchased from Invitrogen, except dNTPs, which were from Qiagen) was added to each sample and incubated for $50 \mathrm{~min}$ at $42{ }^{\circ} \mathrm{C}$ and $10 \mathrm{~min}$ at $70{ }^{\circ} \mathrm{C}$. PCR was performed with cDNA samples using the following protocol: $2 \mu \mathrm{cDNA}$ as template, $2 \mu \mathrm{MgCl}_{2}(25 \mathrm{mM}), 2.5 \mu \mathrm{l} 10 \times$ PCR buffer II, $0.75 \mu \mathrm{l}$ dNTPs $(10 \mathrm{mM}), 0.75 \mu \mathrm{l}$ of each primer $(10 \mu \mathrm{M}), 0.25 \mu \mathrm{l}$ AmpliTaq Gold DNA Polymerase (5 U/ $\mu \mathrm{l}$; all reagents were obtained from Applied Biosystems, Darmstadt/Germany), and $16.75 \mu \mathrm{l} \mathrm{H}_{2} \mathrm{O}$. The following cycling conditions were chosen: initial denaturation at $95^{\circ} \mathrm{C}$ for $12 \mathrm{~min}$, followed by 39 cycles of $30 \mathrm{~s}$ at $95^{\circ} \mathrm{C}, 30 \mathrm{~s}$ at $60{ }^{\circ} \mathrm{C}, 30 \mathrm{~s}$ at $72^{\circ} \mathrm{C}$, and a final extension at $72{ }^{\circ} \mathrm{C}$ for $7 \mathrm{~min}$. Controls without RT were performed for colon, olfactory mucosa, vagina, and diaphragm. The primers used in the study were for Olfr78: fwd: CCT GCT GCT CTC CTT GAG TA; rev: AGT GAG CTT CCT CCA GTC CT; product length: 159 bp and for $\beta$-actin: fwd: GTG GGA ATG GGT CAG AAG G; rev: GGC ATA CAG GGA CAG CAC A; product length: $300 \mathrm{bp}$. Control reactions were run in the absence of reverse transcriptase and in the absence of DNA template, respectively. The PCR products were separated by electrophoresis on a $2 \%$ Trisacetate-EDTA agarose gel. For subsequent sequencing, PCR products were purified using the Monarch DNA Gel Extraction Kit (New England Biolabs, Frankfurt, Germany) as recommended by the manufacturer. Sequencing was done by Eurofins (Ebersberg, Germany). 
Table 1 Analysis of Olfr78 mRNA expression and X-gal staining in murine organs

\begin{tabular}{|c|c|c|}
\hline Organ/tissue & $\begin{array}{l}\text { Olfr78-positive samples/total } \\
\beta \text {-actin-positive samples }\end{array}$ & Localisation of X-gal staining \\
\hline $\begin{array}{l}\text { Superior cervical } \\
\text { ganglion + carotid } \\
\text { body }\end{array}$ & $5 / 5$ & Glomus cells of the carotid body \\
\hline Olfactory mucosa & $5 / 5$ & Some olfactory neurons \\
\hline Tongue & $4 / 5$ & Small vessels \\
\hline Outer ocular muscle & $5 / 5$ & Small vessels \\
\hline Cheek muscle & $4 / 4$ & Small vessels \\
\hline Thigh muscle & $1 / 2$ & Small vessels \\
\hline Diaphragm & $5 / 5$ & Small vessels \\
\hline Intercostal muscle & $1 / 1$ & Small vessels \\
\hline Heart ventricles & $3 / 4$ & Small vessels \\
\hline Atrial auricles & $5 / 5$ & Almost completely neg \\
\hline Apex cordis & $3 / 3$ & Small vessels \\
\hline Trachea & $1 / 1$ & Very few small vessels \\
\hline Lung & $2 / 5$ & Negative \\
\hline Oesophagus & $1 / 1$ & Very few small vessels \\
\hline Stomach & $4 / 5$ & Very few small vessels (not shown) \\
\hline Small intestine & $1 / 5$ & Very few small vessels (not shown) \\
\hline Colon & $5 / 5$ & Some small vessels + enteroendocrine cells \\
\hline Liver & $1 / 5$ & Negative \\
\hline Gallbladder & $4 / 5$ & Cystic artery \\
\hline Kidney & $2 / 5$ & Specific vascular segments \\
\hline Urinary bladder & $5 / 5$ & Very few small vessels \\
\hline Adrenal gland & $5 / 5$ & Negative \\
\hline Thymus & $4 / 5$ & Negative (not shown) \\
\hline Spleen & $1 / 4$ & Negative \\
\hline Lymph node & $1 / 2$ & Not analysed \\
\hline Testis & $2 / 2$ & Small vessels and maturing sperm \\
\hline Epididymis & $2 / 2$ & Some small vessels \\
\hline Prostate & $2 / 2$ & Not analysed due to high endogenous X-gal activity \\
\hline Seminal vesicle & $0 / 1$ & Negative \\
\hline Ovary & $3 / 3$ & Negative \\
\hline Oviduct & $3 / 3$ & Some small vessels \\
\hline Uterine horn & $3 / 3$ & Some small vessels \\
\hline Uterine fundus & $3 / 3$ & Small vessels \\
\hline Vagina & $2 / 3$ & Some small vessels (not shown) \\
\hline Adipose tissue & $1 / 1$ & Some small vessels \\
\hline Dorsal root ganglia & $0 / 1$ & Negative \\
\hline Femoral artery & $3 / 5$ & Positive smooth muscle cells \\
\hline Femoral vein & $1 / 5$ & Negative \\
\hline Femoral nerve & $0 / 4$ & Negative \\
\hline Auricle of the ear & $3 / 5$ & Negative \\
\hline
\end{tabular}

\section{Whole-mount X-gal staining of mouse organs and tissues}

Mice were killed by inhalation of an overdose of isoflurane (Baxter, Unterschleissheim, Germany) and exsanguination. Organs/organ packages and skin-free hind limbs with part of the pelvis were dissected and immediately transferred into
$4{ }^{\circ} \mathrm{C}$ cold $4 \%$ paraformaldehyde (PFA) in $0.1 \mathrm{M}$ phosphate buffer. Samples were kept on ice for $1 \mathrm{~h}$ and subsequently washed with $4{ }^{\circ} \mathrm{C}$ cold washing buffer [phosphate-buffered saline (PBS), $\mathrm{pH} 7.4,2 \mathrm{mM} \mathrm{MgCl} 2,0.01 \mathrm{mM}$ sodium deoxycholate, $0.02 \%$ octylphenoxypolyethoxyethanol (IGEPAL CA-630)] followed by two washing steps using the same buffer at room temperature. The washing buffer 
was replaced by staining solution $[0.1 \mathrm{M}$ Tris- $\mathrm{HCl} \mathrm{pH}$ 7.5, $2 \mathrm{mM} \mathrm{MgCl}$, 0.02\% IGEPAL CA-630, 0.01\% sodium deoxycholate, $5 \mathrm{mM}$ potassium ferricyanide, $5 \mathrm{mM}$ potassium ferrocyanide, $1 \mathrm{mg} / \mathrm{ml}$ 5-bromo-4-chloro-3-indoxyl$\beta$-D-galactopyranoside (X-gal; prepared from a $20 \mathrm{mg} / \mathrm{ml}$ stock solution in DMSO)] and samples were incubated light protected overnight at room temperature. Next day, samples were washed three times with PBS, pH 7.4. Photographs were taken with a Zoom Stereo Olympus SZ40 microscope equipped with a camera port and a transmitted light base. For this purpose, samples were fixed with fine pins either on the bottom of a delta T-dish covered with a thin layer of transparent Sylgard polymer (Dow Corning, Wiesbaden, Germany) or on pieces of pink dental wax. All the time samples were submerged in PBS.

\section{Frozen sections of whole-mount X-gal-stained mouse organs and tissues}

After taking photographs, whole-mount samples were fixed again with $4 \%$ PFA overnight at $4{ }^{\circ} \mathrm{C}$. Fixative was removed by washing with $0.1 \mathrm{M}$ phosphate buffer $\mathrm{pH} 7.4$ (PP) followed by incubations in the same buffer with $9 \%$ and $30 \%$ sucrose, respectively. Samples were placed in cryo-embedding medium (Tissue-Tek, Sakura, Umkirch, Germany) and shock-frozen in liquid nitrogen. Next, samples were sectioned at $10 \mu \mathrm{m}$ thickness with a cryostat microtome (Leica CM 1900, Wetzlar, Germany), mounted onto Superfrost Plus glass slides (R. Langenbrinck, Emmendingen, Germany), and air-dried. After embedding in Mowiol 4-88 (pH 8.6; Merck, Darmstadt, Germany) sections were examined under a Zeiss Axioplan 2 microscope (Jena, Germany) and photographs were taken.

Organs (liver, kidney, heart, testis) from one reporter mouse were used for immunohistological localisation of $\alpha$-smooth muscle actin. We applied FITC-conjugated anti- $\alpha-$ smooth muscle actin antibody [mouse monoclonal antibody clone 1A4; F3777; diluted 1:2.000 in PBS (Sigma-Aldrich, Taufkirchen, Germany)] or Cy3-conjugated anti- $\alpha$-smooth muscle actin antibody [mouse monoclonal antibody clone 1A4; C6198; diluted 1:1.600 in PBS (Sigma-Aldrich)] to frozen sections for $1 \mathrm{~h}$ at room temperature to identify smooth muscle cells. Abcam, a manufacturer that also offers the mouse monoclonal antibody clone $1 \mathrm{~A} 4$, reports that the antibody was knockout validated (https://www.abcam.com/ alpha-smooth-muscle-actin-antibody-1a4-ab7817.html).

\section{Tissue clearing of whole mounts}

In case of two mice, tissue clearing was performed to optimize visualization of $\mathrm{X}$-gal staining following the protocol given by Treweek et al. (2015). Briefly, samples were incubated in A4P0 Hydrogel solution prepared by mixing $20 \mathrm{ml}$ of $40 \%$ acrylamide (wt/vol) (Sigma-Aldrich) and $20 \mathrm{ml}$ of $10 \times$ PBS with $160 \mathrm{ml}$ of ice-cold $\mathrm{H}_{2} \mathrm{O}$. Immediately before use, $500 \mathrm{mg}$ thermoinitiator $\left(2,2^{\prime}\right.$,-azobis [2-(2-imidazolin2-yl)propane] dihydrochloride) (FUJIFILM Wako Chemicals Europe GmbH, Neuss, Germany) was stirred into the solution. For penetration, samples were incubated with A4P0 hydrogel solution over night at $4{ }^{\circ} \mathrm{C}$. Next day polymerisation of the hydrogel solution was induced by incubating the samples in a $37^{\circ} \mathrm{C}$ warm water bath. Subsequently, polymerized hydrogel attached to the surface of the samples was removed and samples were washed with PBS. For elution of lipids, samples were incubated in PBS-8\% sodium dodecyl sulphate (Carl Roth, Karlsruhe, Germany), which was replaced daily by fresh solution. Over the coming days, progress in tissue clearing was checked microscopically.

\section{Results}

\section{Olfr78 mRNA expression in murine organs}

We performed RT-PCR to analyse expression of Olfr78 at the level of mRNA (Fig. 1). $\beta$-Actin mRNA served as quality control (not shown); only samples for which we obtained a clear $\beta$-actin PCR product were included in the summary (Table 1). Olfr78 expression was detectable in a large number of murine organs. We obtained PCR products for all samples of superior cervical ganglion with attached carotid body, olfactory mucosa, outer ocular muscle, cheek muscle, diaphragm, intercostal muscle, atrial auricles, apex cordis, trachea, oesophagus, colon, urinary bladder, adrenal gland, testis, epididymis, prostate, ovary, oviduct, uterus, and adipose tissue. Olfr78 mRNA was not in or not in all samples of the following organs detectable: tongue $(4 / 5=4$ out of 5 samples were positive), thigh muscle (1/2), heart ventricle (3/4), lung (2/5), stomach (4/5), small intestine (1/5), liver (1/5), gallbladder (4/5), spleen (1/4), thymus (4/5), lymph node $(1 / 2)$, seminal vesicle $(0 / 1)$, vagina $(2 / 3)$, auricle of the ear (3/5), DRGs (0/1), femoral vein (1/5), and femoral nerve (0/4). Olfr78 mRNA was expressed in three out of five samples of femoral artery. Surprisingly, just two out of five kidneys were Olfr78 positive.

Next, we used the mouse strain CD1;129-Olfr $78^{\text {tmljgst }}$ to clarify which cells of the organs/tissues express Olfr78.

\section{Differentiation between endogenous $\beta$-galactosidase activity and that resulting from lacZ gene expression}

In the mouse strain CD1;129-Olfr $78^{\text {tm1jgst }}$ green fluorescent protein (GFP) and tau/ $\beta$-galactosidase are co-expressed with Olfr78. We decided to focus on $\beta$-galactosidase as histological marker because it enabled the analysis of both whole 


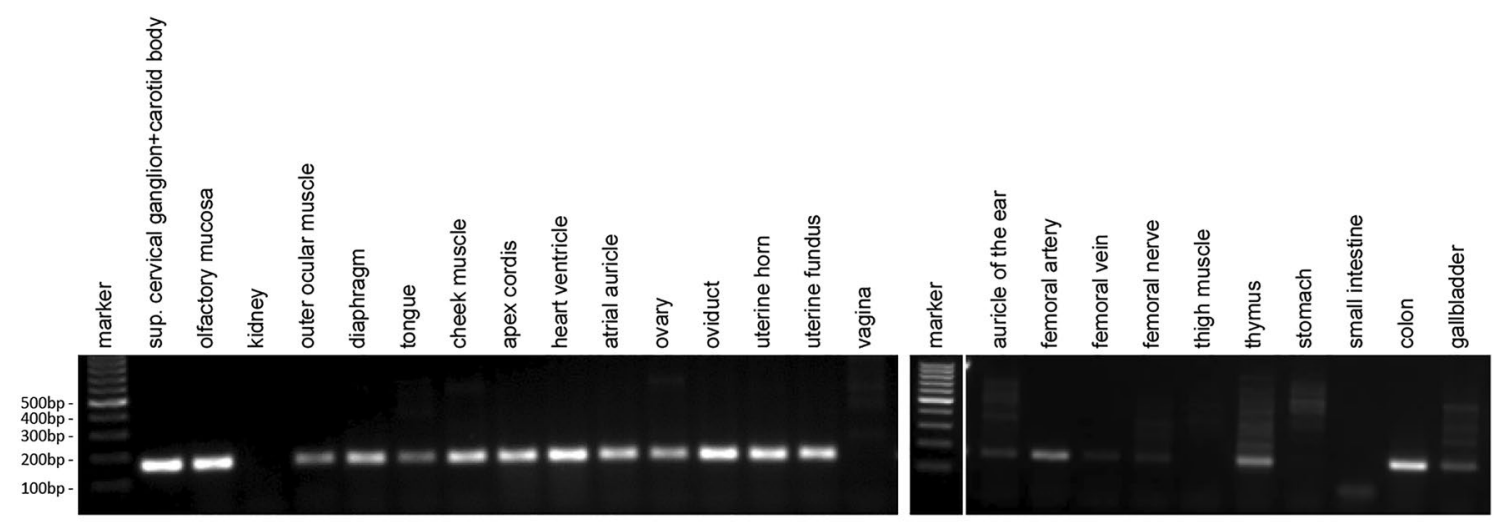

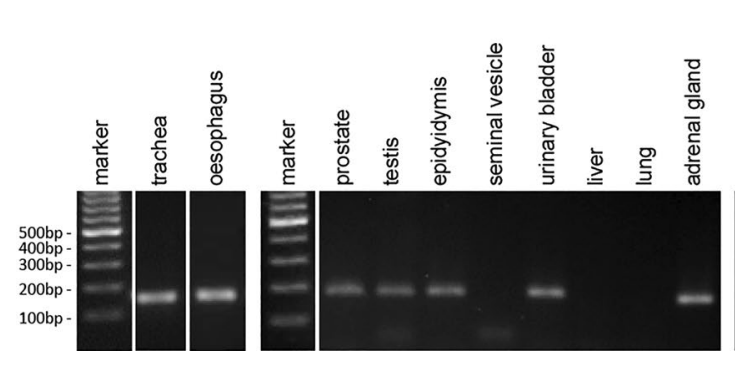

Fig. 1 Expression of Olfr78 mRNA transcripts in murine organs. The RT-PCR product was of the expected size and specificity was confirmed by sequencing. For colon, control run without reverse transcriptase (control $\emptyset \mathrm{RT})$ and control without template $\left(\mathrm{H}_{2} \mathrm{O}\right.$ control) are shown. The data shown are from organs and tissues isolated

organs for Olfr78 expression and frozen sections generated from these organs.

$\mathrm{X}$-gal is a commonly used substrate for the detection of bacterial $\beta$-galactosidase (lacZ). Most mammalian $\beta$-galactosidases have an acidic $\mathrm{pH}$ optimum whereas the bacterial X-gal enzyme works best at neutral $\mathrm{pH}$. However, Weiss et al. (1999) have shown that at pH 7.5-which is recommended in most $\mathrm{X}$-gal staining protocols and which we have used too-both endogenous and bacterial $\beta$-galactosidase may be active. Therefore, we compared $\mathrm{X}$-gal staining of whole organs from C57B16 (Fig. 2a, a', $c$, e) and Olfr78 reporter mice $\left(\mathrm{CD} 1 ; 129-\mathrm{Olfr} 78^{\mathrm{tm} 1 / \mathrm{gst}}\right.$; Fig. 2b, b', d, f). The heart of the C57B16 mouse was negative (Fig. 2a, $a^{\prime}$ ), whereas in the heart of the reporter mouse (Fig. 2b, b') X-gal reaction product was detectable in small vessels of the ventricles. Accordingly, X-gal-positive vessels were present in frozen sections of hearts from reporter mice, but not from C57B16 animals (Fig. 2 c, d). In the male reproductive tract, however, endogenous $\beta$-galactosidase activity resulted in staining of prostate, epididymis, and deferent duct of both mouse strains (Fig. 2 e, f). Staining of testis was restricted to the reporter mice indicating Olfr78 expression in this organ (Fig. 2f). In the following, we will present data only from findings in reporter mice.

In summary, most X-gal-positive cells were located in the walls of specific vascular beds. In particular, blood vessels from four mice. Individual agarose gels are separated by wide white spaces and samples that were separated on the same gel but not next to each other by narrow white spaces. Marker: 100 bp molecular weight marker

supplying striated muscles of the musculoskeletal system and of the heart showed pronounced X-gal staining. Additionally, we observed staining of non-vascular cells. The expression of Olfr78 in non-sexual organs was comparable in male and female mice.

\section{Skeletal muscles are supplied with blood by vessels exhibiting Olfr78-expressing cells}

Pluznick et al. have described the expression of Olfr78 in small resistance vessels supplying the diaphragm and some non-specified skeletal muscles (Pluznick et al. 2013). We confirmed and extended these findings by analysing the diaphragm and defined skeletal muscles taken from all major regions of the body (Figs. 3 and 4). In the diaphragm, X-galpositive vessels were arranged in a dense network, which was detectable in both whole-mount samples and frozen sections (Fig. 3a-c). We also found X-gal staining in small vessels feeding the intrinsic muscles of the tongue (Fig. 3d-f) and the extrinsic muscles of the eyeball (Fig. 3g-i). Nerve fibres supplying these striated muscles (Fig. 3i) and the optic nerve (Fig. 3g) were X-gal negative. The microvasculature of intercostal muscles of the chest (Fig. 3j, k, k'), thigh muscles (Fig. 4a, c, d), and muscles of the pelvic floor (Fig. 7i) was X-gal positive, too. Furthermore, we observed X-galstained vessels in facial muscles at the tip of the nose, cheek 


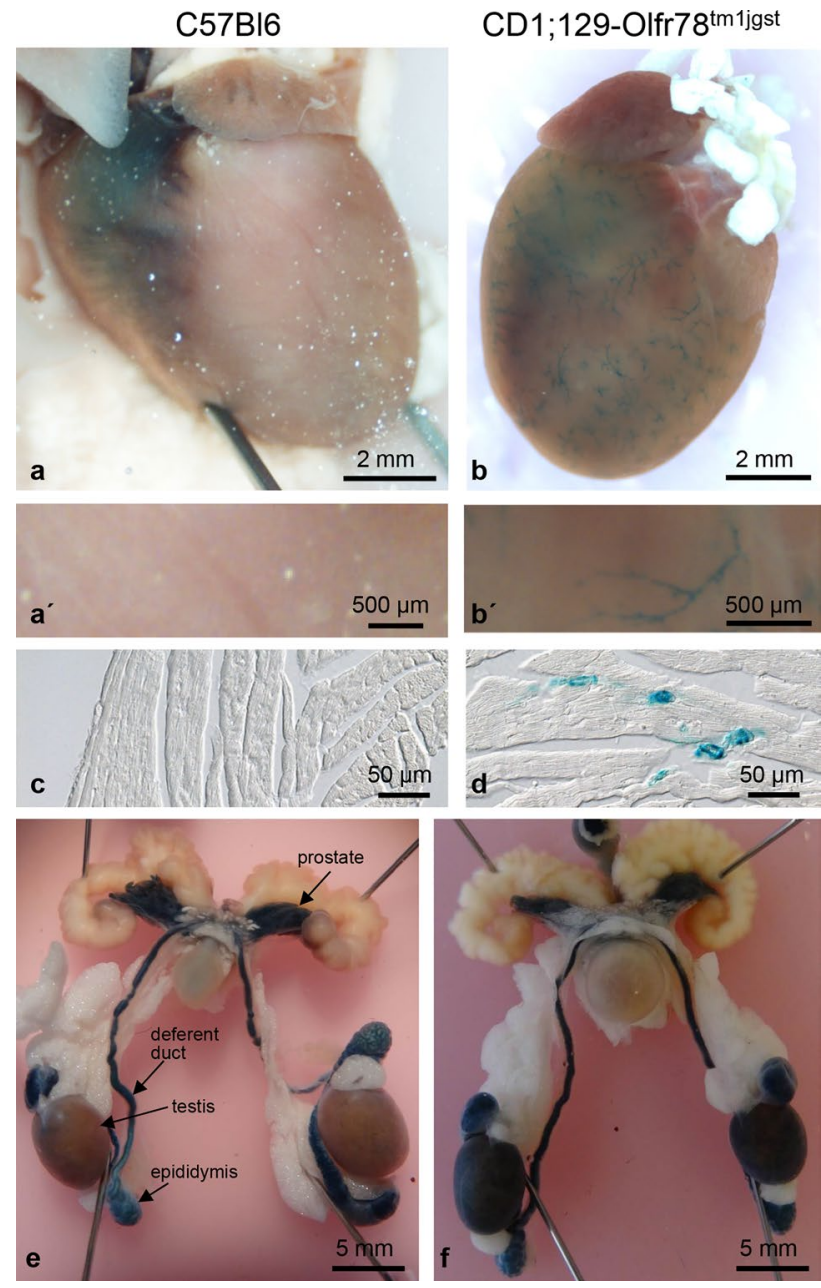

Fig. 2 Differentiation between endogenous $\beta$-galactosidase activity and that resulting from tau-lacZ gene expression. X-gal staining of whole hearts $(\mathbf{a}, \mathbf{b})$ and corresponding frozen sections $(\mathbf{c}, \mathbf{d})$ of a nontransgenic C57B16 mouse $(\mathbf{a}, \mathbf{c})$ and of a CD1;129-Olfr78 ${ }^{\text {tmljgst }}$ mouse (=Olfr78 reporter mouse) (b, d). $\mathbf{a}^{\prime}, \mathbf{b}^{\prime}$ details of the ventricle walls of whole hearts at higher magnification. Whole-mount X-gal staining of male reproductive tract of a nontransgenic C57B16 mouse (e) and an Olfr78 reporter mouse (f). Endogenous X-gal activity is detectable in epididymis, deferent ducts, and prostate, and staining of testis is restricted to the reporter mouse

muscles, and muscles of the floor of the mouth (not shown). The outer diameter of most of these intensively stained small vessels was in the range of 6 to $12 \mu \mathrm{m}$.

With exception of the hind limbs, staining was restricted to the microvasculature whereas large(r) vessels were unlabelled. The internal thoracic artery and the intercostal arteries were unlabelled whereas the small vessels running in the intercostal muscles exhibited distinct staining (Fig. 3j, k). Branches arising from these small vessels rapidly lost their labelling (Fig. 3k, $\mathrm{k}^{\prime}$ ), indicating that Olfr78 expression is restricted to very specific vascular segments.

The vasculature supplying the skeletal muscles of the hind limbs showed a distinct pattern of Olfr78 distribution in that large vessels were stained in this body region. Interestingly, occurrence of Olfr78 reporter-positive cells changed along the course of the vessel from the pelvis towards the hind paw: the main feeding artery starting in the pelvisthe external iliac artery-was completely negative (Fig. 4a). $\mathrm{X}$-gal staining of the neighbouring small vessels running in the muscles indicates that this was not due to insufficient penetration with reaction solution (Fig. 4a, c). After undercrossing the inguinal ligament, the vessel-now called femoral artery-became increasingly X-gal positive (Fig. 4a, b). When it crossed the distal thigh and became the saphenous artery, intense labelling became obvious, which was detectable until the X-gal signal disappeared in the region of the lower leg (Fig. 4a). Vascular staining was not homogeneous: it was caused by X-gal-positive cells circularly arranged in the arterial wall (Fig. 4b). Along the entire course of the artery, the accompanying vein and nerve were negative (Fig. 4b). As in skeletal muscles of other regions, small $\mathrm{X}$-gal-positive vessels formed a network within the musculature that was also detectable in frozen sections (Fig. 4d).

$\mathrm{X}$-gal staining was not restricted to small vessels feeding the striated muscles of the musculoskeletal system, but also detectable in the vessels supplying the striated muscles of the heart (Figs. 2 and 5). In cleared hearts, the network of X-gal-positive vessels was particularly well recognizable in the ventricles (Fig. 5a, b) but hardly detectable in the atria (Fig. 5a). In the heart, X-gal-positive vessels reached diameters up to $30 \mu \mathrm{m}$. In contrast to these small blood vessels (Fig. 5b, d), the large vessels feeding this network were $\mathrm{X}$-gal negative (Fig. 5b) as could also be seen in frozen sections (Fig. 5c).

\section{Organ-specific differences in the contribution of Olfr78 reporter-expressing vessels to the blood supply}

Additionally, we screened many murine organs for X-gal expression; these findings are compiled in Figs. 6, 7, 8, 9. In summary, most of the X-gal-positive cells were located in vessels supplying the organs with blood.

Vascular LacZ expression differed distinctly between organs. We did not detect vessels with X-gal-positive cells in lung (Fig. 6d-f), liver (Fig. 6j-1), adrenal gland (Fig. 7m, n), spleen (Fig. 7k, 1), seminal vesicle (Fig. 8g, h), ovary (Fig. 8i, j), dorsal root ganglia (DRGs), and spinal nerves (Fig. 8o-q). In the urinary bladder, X-gal-positive small vessels were so rare that we detected them in whole mounts of the organs but not in frozen sections (Fig. $7 \mathrm{~h}-\mathrm{j}$ ). In trachea (Fig. 6a-c) and the oesophagus (Fig. 6g, h) only individual small vessels were $\mathrm{X}$-gal positive. In the gallbladder, we regularly observed staining of the cystic artery, but to a variable degree between animals (Fig. 6m, n). Vessels exhibiting X-gal-positive cells were consistently found in 


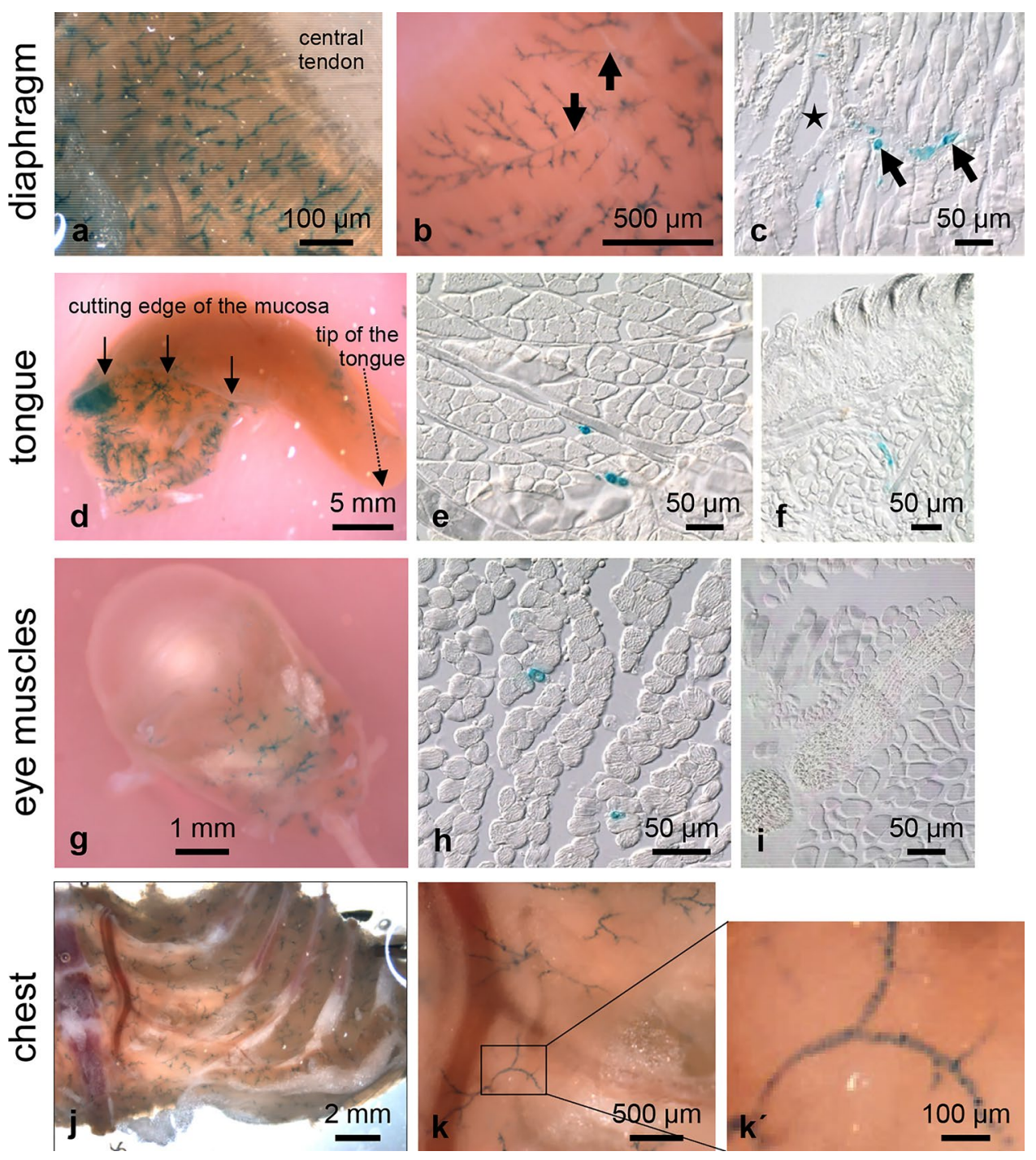

Fig. 3 X-gal-positive small vessels supplying striated muscles of various regions of the mouse body. The muscle of the diaphragm, but not the central tendon, possesses X-gal-positive vessels (a). At higher magnification, strong X-gal staining of small vessels can be seen, whereas larger vessels (arrows) show weak or no labelling (b). Corresponding frozen section of the diaphragm showing a larger, negative vessel (asterisk) and small, positive vessels (arrows) (c). In the tongue, penetration of the solutions necessary for X-gal staining is restricted by the mucosa wrapping the muscular body. In the region of removed mucosa, a distinct X-gal labelling of small vessels supplying the skeletal muscle is obvious (d). Frozen section of the tongue

colon (Fig. 9c, d), kidney (Fig. 7a-g), testis (Fig. 8a-d), epididymis (Fig. 8f), oviduct (Fig. 8i, k), and uterus (Fig. 81, $\mathrm{m})$. X-gal staining, however, was not continuous along the arterial supply in any of these organs. In colonic vessels, cells of different staining intensities including negative cells alternated in an irregular order (Fig. 9d').

In the kidney, the various segments of vessels had different staining patterns (Fig. 7a-g). X-gal-positive cells were restricted to arteries and not detectable in accompanying with small X-gal-stained vessels (e). No X-gal-positive cells are detectable in the epithelium of the dorsum of the tongue (f). Wholemount X-gal staining of the eye (g) reveals small positive vessels running in the extraocular muscles (clearing of the sample for 19 days); the corresponding frozen section is shown in (h). Nerve fibers running between the muscle fibers are negative (i). Whole-mount X-gal staining of the chest (j) demonstrates that small vessels supplying the intercostal muscles are X-gal positive, whereas the larger vessels are negative (k). The boxed area marked in (k) is given at higher magnification in $\left(\mathbf{k}^{\prime}\right)$ to demonstrate the circular arrangement of the X-galpositive cells in the vessel wall

veins (Fig. 7e, e'). The main branches of the renal artery (external diameter about $200 \mu \mathrm{m}$ ) were covered by circularly arranged positive cells. The density of these cells rapidly decreased on the way of the vessel from the hilum to the cortex (Fig. 7b, c). However, the vascular section in which loss of X-gal-positive cells occurred varied between individual animals ranging from relatively near to the hilum to somewhere in the cortex region. The following vessel segment (medium-sized vessels with external diameters 
Fig. 4 Large and small arteries of the hind limb exhibit X-galpositive segments. Overview of whole-mount X-gal staining of part of the opened pelvis and hind limb after removal of skin and fat tissue (a). The external iliac artery running in the pelvic is X-gal negative. After crossing the inguinal ligament (dashed blue line), the vessel is called the femoral artery. It becomes X-gal positive in its course to the thigh. When the femoral artery continues into the saphenous artery, it exhibits continuously increasing X-gal staining intensity. Higher magnification reveals the circular arrangement of X-gal-stained cells of the arterial wall. The accompanying saphenous vein (b). Small vessels supplying the skeletal muscles show strong $\mathrm{X}$-gal staining (c) as can also be seen in the corresponding frozen section (d) the medial aspect of the left and femoral nerve are unstained

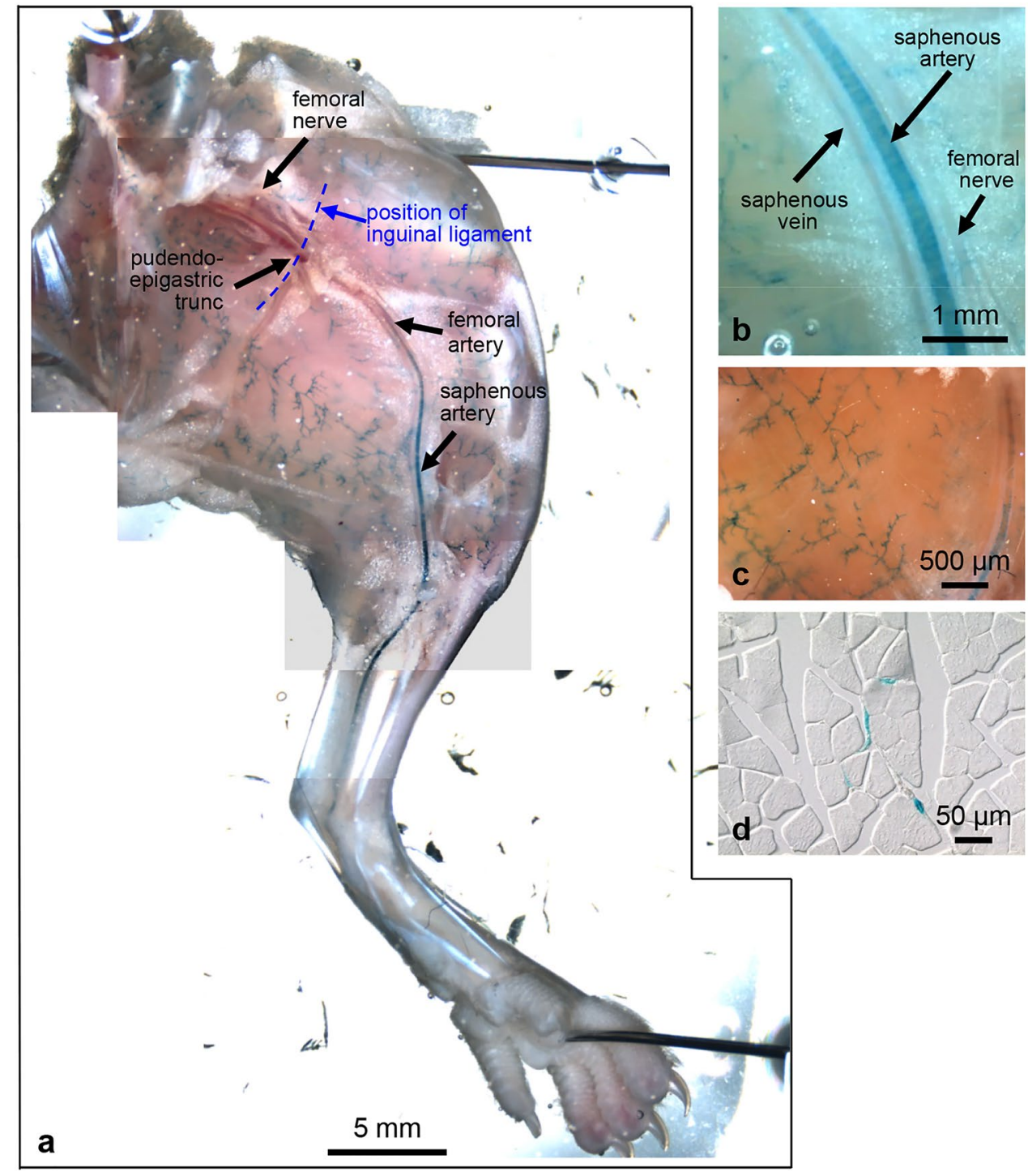

Fig. $5 \mathrm{X}$-gal staining of the heart. Whole-mount heart cleared for 10 days with intensively stained small vessels (a). Heart ventricles exhibit a dense network of X-gal-positive small vessels, whereas atria are almost negative (asterisks in a). Major coronary arteries (long arrows) and their main branches (short arrows) are X-gal negative (b). Frozen sections showing a large, $\mathrm{X}$-gal-negative (c) and small, X-gal-positive vessel (d)
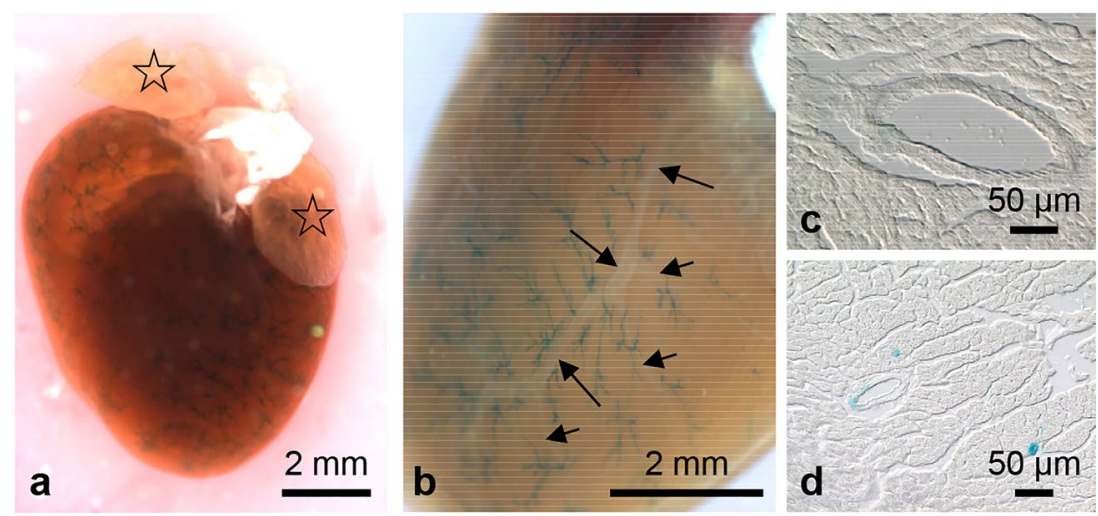

between 100 and $200 \mu \mathrm{m}$ ) had no positive or just a few positive cells (Fig. 7e). Smaller vessels with diameter between 30 to $100 \mu \mathrm{m}$ were mostly negative (Fig. 7f). Some of the small vessels in close proximity of glomeruli (outer diameter between 7 and $11 \mu \mathrm{m}$ )—probably afferent arterioles-showed strong staining.

In the testis, small vessels running between the seminiferous tubules (Fig. 8c, d) were strongly stained. This 
Fig. 6 Whole-mount X-gal staining of respiratory and gastrointestinal organs. In the longitudinally opened trachea (a), X-gal-positive cells are hardly detectable. An individual small vessel with $\mathrm{X}$-gal-positive cells (arrow) can be seen at higher magnification in (b). Corresponding frozen section with a small X-gal-positive vessel in the tracheal adventitia (c). $\mathrm{X}$-gal staining cannot be seen in the overview of both lungs (d), at higher magnification of one lobe (e), or in frozen sections (f). In the oesophagus, only a few small X-gal-positive vessels are detectable (g, arrows in $\mathbf{h}$ ). Corresponding frozen section without X-gal reaction product (i). Whole-mount stained liver (j) and corresponding frozen sections $(\mathbf{k}, \mathbf{l})$ are completely $\mathrm{X}$-gal negative. Smooth muscle actin immunohistochemistry with a Cy3-conjugated antibody was performed to visualize the branches of the hepatic artery and portal vein within Glisson's triad. None of the vessels were $\mathrm{X}$-gal positive $\left(\mathbf{l}, \mathbf{l}^{\prime}\right)$. In gallbladders of two mice, only weak staining of the cystic artery can be seen $(\mathbf{m}, \mathbf{n})$. Corresponding frozen section $(\mathbf{o})$
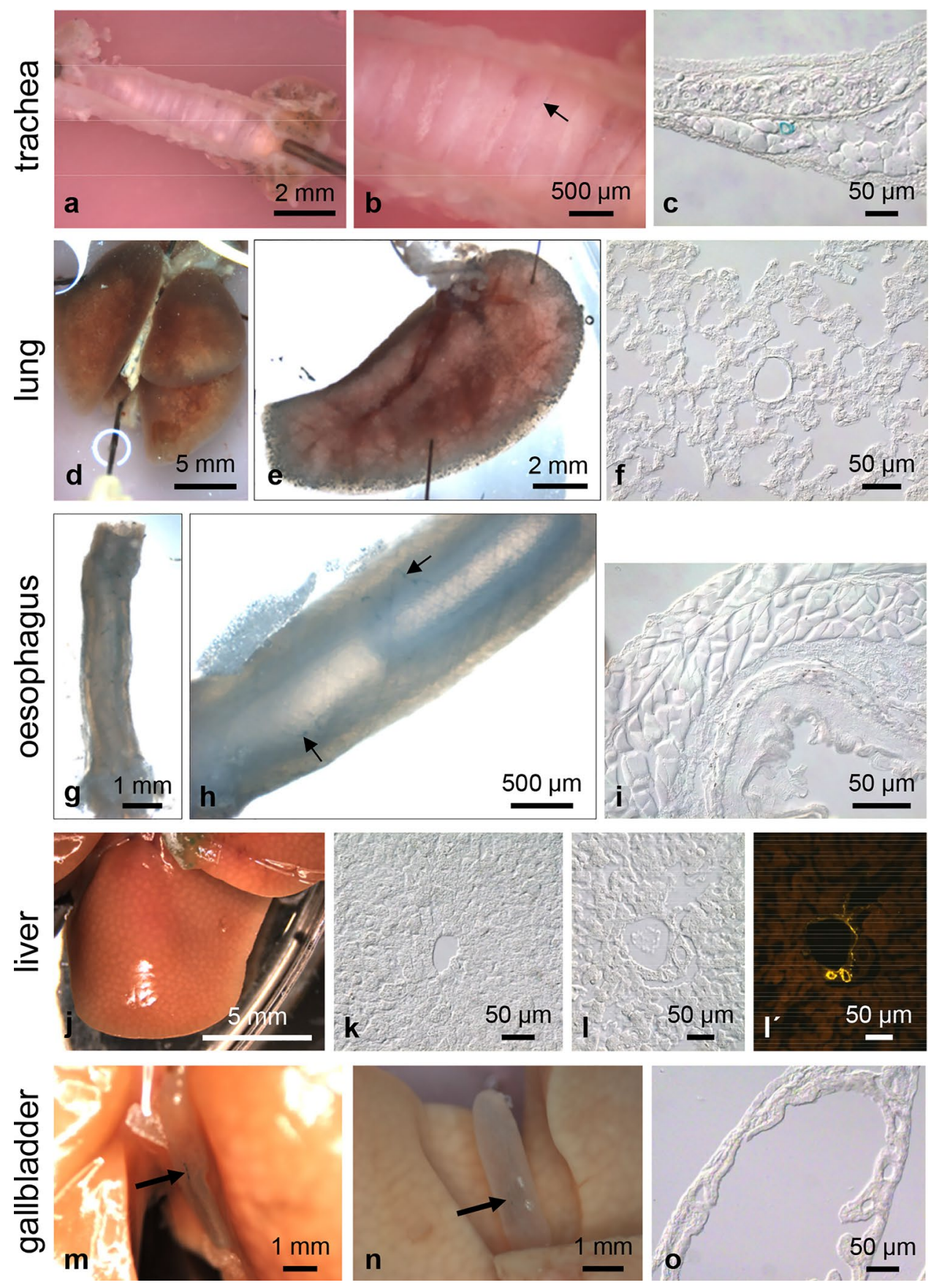

network of vessels was already visible from the outer aspect of the intact testis (Fig. 8a, b). In the female reproductive tract, the ovary was found to be $\mathrm{X}$-gal negative (Fig. 8i, j). In the oviduct, we observed small X-gal-positive vessels in both the whole organ and frozen sections (Fig. 8i, k). The uterine fundus showed a relatively high density of X-gal-positive vessels (Fig. 81) and in frozen sections these stained vessels were detectable in the myometrium (Fig. $8 \mathrm{~m}$ ); the epithelium exhibited no X-galpositive cells (Fig. 8n).

\section{Olfr78 reporter-expressing cells in the vessel wall are smooth muscle cells}

Frozen sections of kidney, heart ventricles, and testis with $\mathrm{X}$-gal-positive vessels were labelled with FITC- or Cy3conjugated anti- $\alpha$-smooth muscle actin antibody to identify smooth muscle cells, revealing colocalization of the signals (Figs. 7e, e' and 10). 
Fig. 7 Whole-mount X-gal staining of murine organs. Kidney is the only region of the murine body other than the hind limb in which we observed larger X-gal-positive vessels (a) In a kidney cleared for 19 days (b), positive vessels enter at the hilum. Higher magnification reveals the circular arrangement of the X-gal-positive cells (c). The frequency of such cells in the vessel wall decreases towards the periphery. Frozen sections demonstrate closely packed X-gal-positive cells in a large vessel (d), a loose arrangement in a medium-sized vessel (e), absence in a small vessel (f), and occurrence in the afferent arteriole of a renal corpuscle (g). X-gal-positive cells are located in the wall of arteries (A), but not of veins (V); smooth muscle cells labelled with Cy3-conjugated smooth muscle actin antibody $\left(\mathbf{e}, \mathbf{e}^{\prime}\right)$. In the urinary bladder, $\mathrm{X}$-gal-positive vessels can be found only sporadically $(\mathbf{h}, \mathbf{i})$. In the vicinity of the urinary bladder, remnants of the pelvic floor muscle with small X-galpositive vessels and parts of the strongly stained deferent duct and prostate can be seen (i). Corresponding frozen section of the urinary bladder (j). Whole mounts of spleen $(\mathbf{k})$ and adrenal gland (m) are X-gal negative as can also be seen in the corresponding frozen sections $(\mathbf{l}, \mathbf{n})$. In the eye $(\mathbf{o})$, apart from the extraocular muscles, no X-gal-positive structures are detectable. Frozen sections from cornea (p) and retina (q) are $\mathrm{X}$-gal negative. Arrows mark the retinal pigmentary epithelium
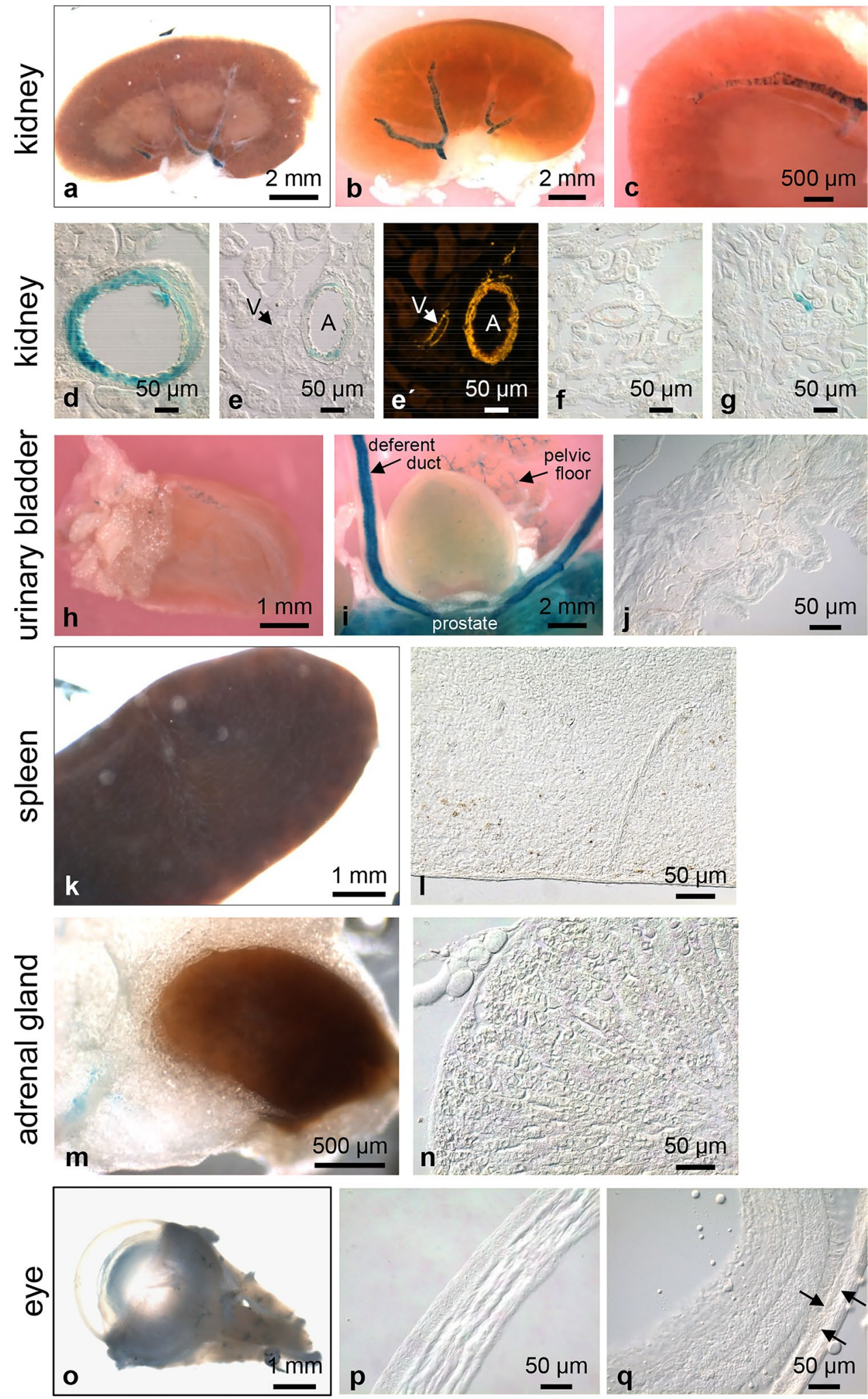

\section{Non-vascular Olfr78 expression}

Abundant Olfr78 expression has been reported previously for the olfactory epithelium and carotid body (Conzelmann et al. 2000; Chang et al. 2015; Zhou et al. 2016). In agreement with Conzelmann et al. (2000), we observed strong $\mathrm{X}$-gal staining of the olfactory epithelium in whole mounts of the nasal cavity (Fig. 11a) and detected individual 
Fig. 8 Whole-mount X-gal staining of genital organs and DRG. In whole-mount testis cleared for 12 days, X-galstained seminiferous tubules and small vessels can be identified $(\mathbf{a}, \mathbf{b})$. In frozen sections, $\mathrm{X}$-gal staining of maturing sperm can be seen. Staining intensity changes in the different development phases. Small vessels running between the tubules are strongly $\mathrm{X}$-gal positive $(\mathbf{c}, \mathbf{d})$. In the epididymis, small vessels are $X$-gal positive (arrows) (f). Staining of the epididymal epithelium is caused by endogeonous $\mathrm{X}$-gal activity as can be seen in frozen sections of WT epididymis (e). The seminal vesicles (seminal v.) are completely X-gal negative (g). Corresponding frozen section (h). In the female reproductive tract, the ovary is X-gal negative (i, j). On the surface of the oviduct (arrows) and in the surrounding adipose tissue, small X-gal-positive vessels are detectable (i). Frozen section of the oviduct with $\mathrm{X}$-gal-positive vessels (k). The uterus-especially the fundus-shows a relatively high density of X-galpositive vessels (l), which can also be seen in frozen sections (m). The epithelium of the uterus is X-gal negative (n). No $X$-gal staining is detectable in DRG and spinal nerve $(\mathbf{o}-\mathbf{q})$
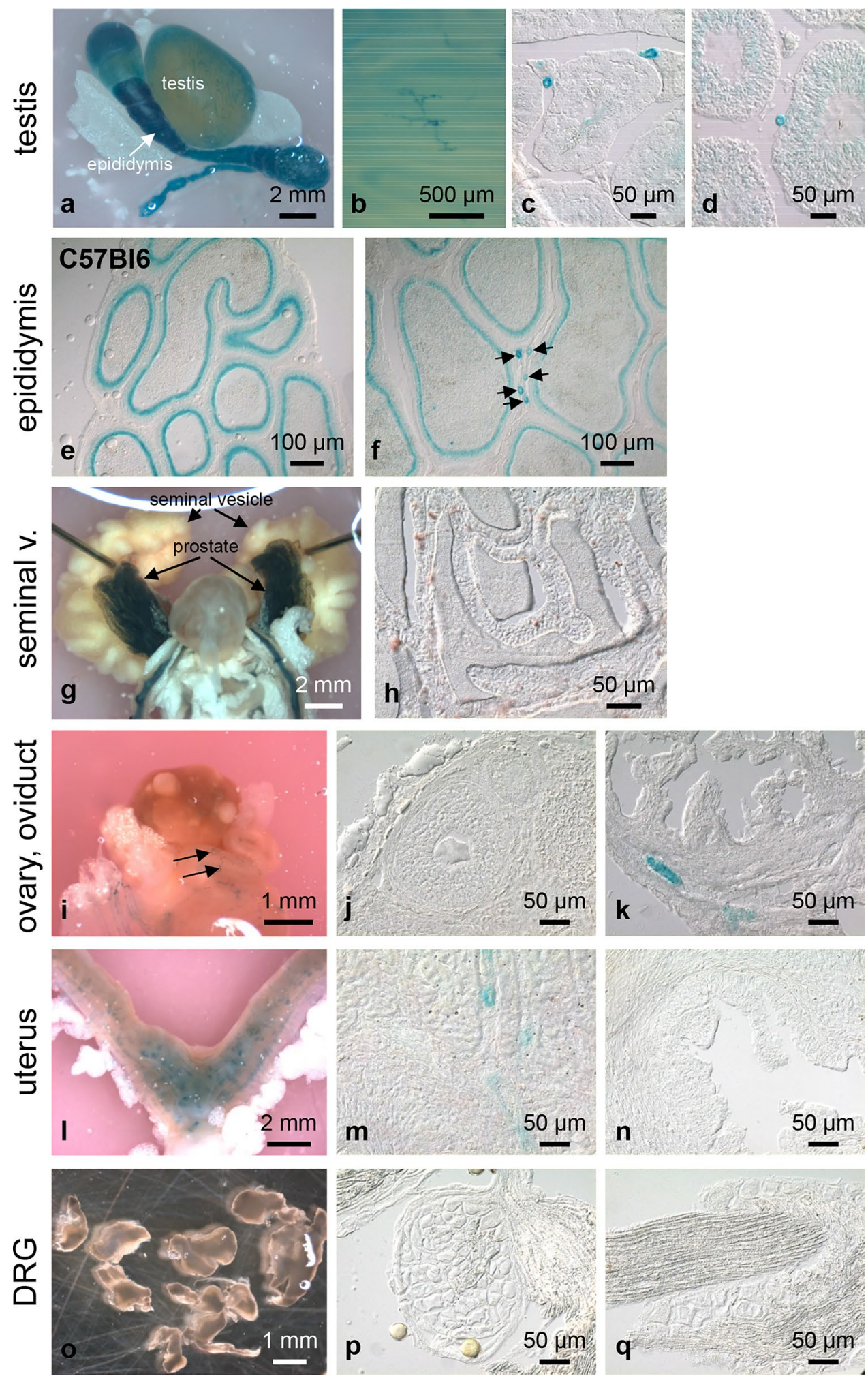

$\mathrm{X}$-gal-positive olfactory neurons in corresponding frozen sections (Fig. 11b). In the carotid body, in addition to the previously reported staining of glomus cells, we observed scattered X-gal-positive small vessels running in the adipose tissue surrounding the carotid body and superior cervical ganglion, whereas the large arteries of the carotid bifurcation were unlabelled (Fig. 11c, d). Fleischer et al. (2015) have described Olfr78 expression by a subset of epithelial cells lining the crypts of the colon and identified these cells as enteroendocrine cells. In line with this report, we also 

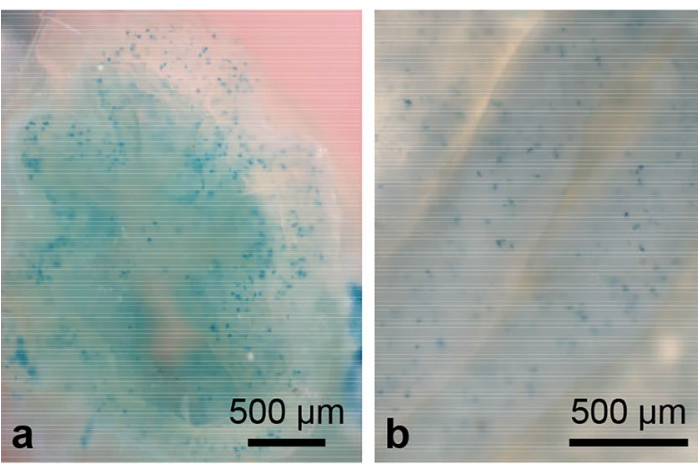

Fig. 9 X-gal staining of the colon. View on a cross-sectioned wholemount colon after clearing for 7 days with dotted X-gal staining pattern of the mucosa (a), which becomes more apparent in a longitudinally opened colon (b). Frozen section showing individual

observed numerous X-gal-positive cells interspersed among the mucosal epithelium in colonic whole mounts (Fig. 9a, b) and sectioned colonic crypts (Fig. 9c). In testis, we observed
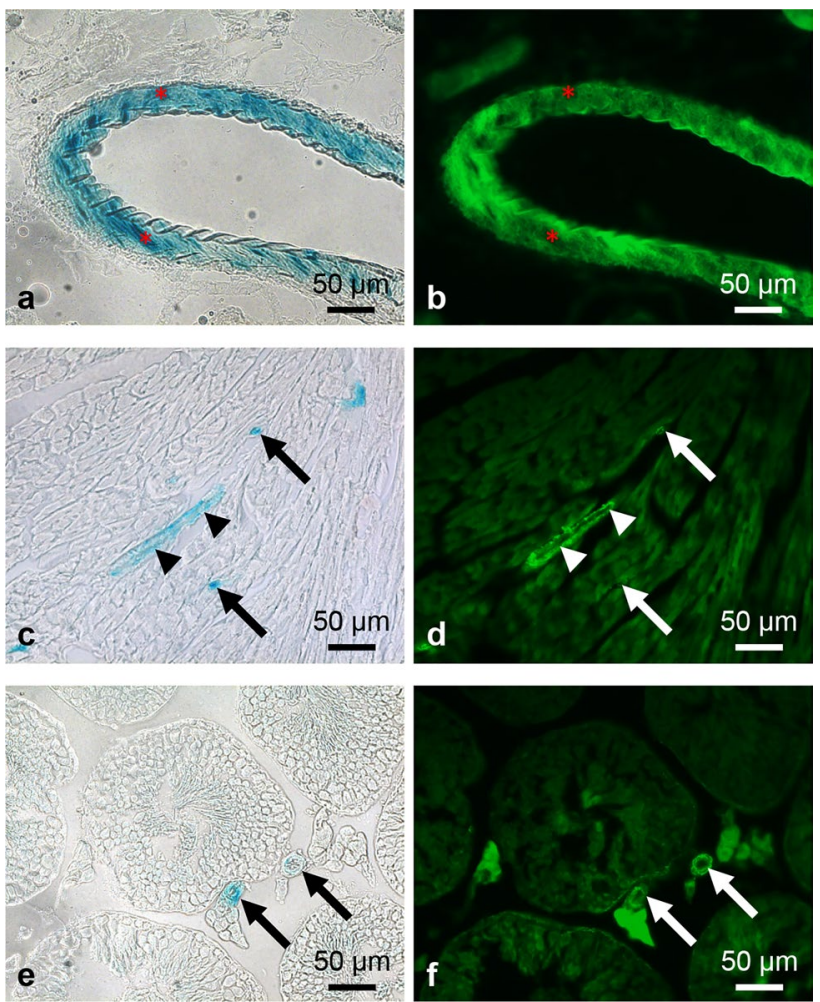

Fig. $10 \mathrm{X}$-gal-positive vascular cells are smooth muscle cells. Frozen sections of whole-mount X-gal-stained kidney $(\mathbf{a}, \mathbf{b})$, heart $(\mathbf{c}, \mathbf{d})$, and testis (e, f) were stained with a FITC-conjugated anti-smooth muscle actin antibody to visualize smooth muscle cells. X-gal reaction product and fluorescence signal are colocalized, indicating Olfr78 expression by smooth muscle cells. However, large amounts of X-gal reaction product prevent binding of the antibody (asterisks in $\mathbf{a}, \mathbf{b}$ ). Arrowheads in $(\mathbf{c}, \mathbf{d})$ point to a longitudinally sectioned small vessel, arrows in $(\mathbf{c}-\mathbf{f})$ to cross sectioned small vessels

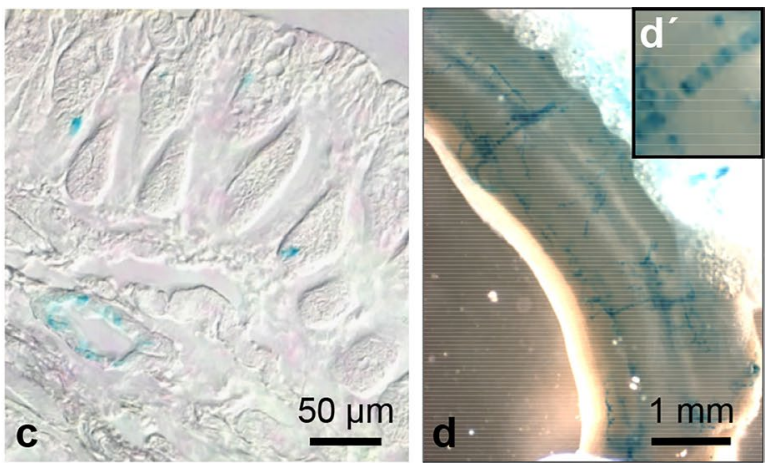

$\mathrm{X}$-gal-positive cells in the colonic epithelium and a small X-gal-positive vessel (c). X-gal-stained vessels running on the outer face of the whole-mount colon are shown in (d). At higher magnification $\left(\mathbf{d}^{\prime}\right)$ the circular arrangement of the X-gal-positive cells can be seen

a weak staining of maturing sperm (Fig. 8c, d). Differences in the intensity of the labelling probably reflect different stages of development of the sperm. Xu et al. (2000) have performed in situ RNA hybridization to demonstrate Olfr78 expression in prostate tissues with a predominant localization in epithelial cells. Due to the high endogenous X-gal activity of prostate (Figs. 2e, 8g), we cannot draw conclusions about Olfr78 expression in this organ (Fig. 2e). We detected Olfr78 expression in neither the retinal pigment cells and choroid as described by Jovancevic et al. (2017) for the human eye (Fig. 7q) nor nervous elements in DRGs, superior cervical ganglion, peripheral nerves, enteric plexuses, and nerve fibres within the organs investigated. Findings obtained by X-gal staining are summarized in Table 1 .

\section{Discussion}

Recently, more and more studies have demonstrated distinct functions of ectopically expressed ORs (Maßberg and Hatt 2018; An and Liggett 2018). Detection of OR transcript is mostly based on RT-PCR, microarray or RNA sequencing techniques. Yet, generation of specific antibodies is difficult since members of OR families have $>40 \%$ sequence identity. The olfactory receptor family 51 (OR51), to which Olfr78 belongs, includes 44 members ("HUGO Gene Nomenclature Committee at the European Bioinformatics Institute"; https://www.genenames.org/data/genegroup/\#!/group/164). Therefore, we have used transgenic mice expressing the lacZ reporter under the control of the Olfr78 promotor to detect Olfr78-expressing cells in many organs and tissues.

We found that in many Olfr78 mRNA-expressing organs, $\mathrm{X}$-gal product was localized in small vessels within the organ and/or running in the surrounding adipose tissue, but not in the parenchyma or in connective tissue cells of the stroma of the organ. The only exceptions that we found were 

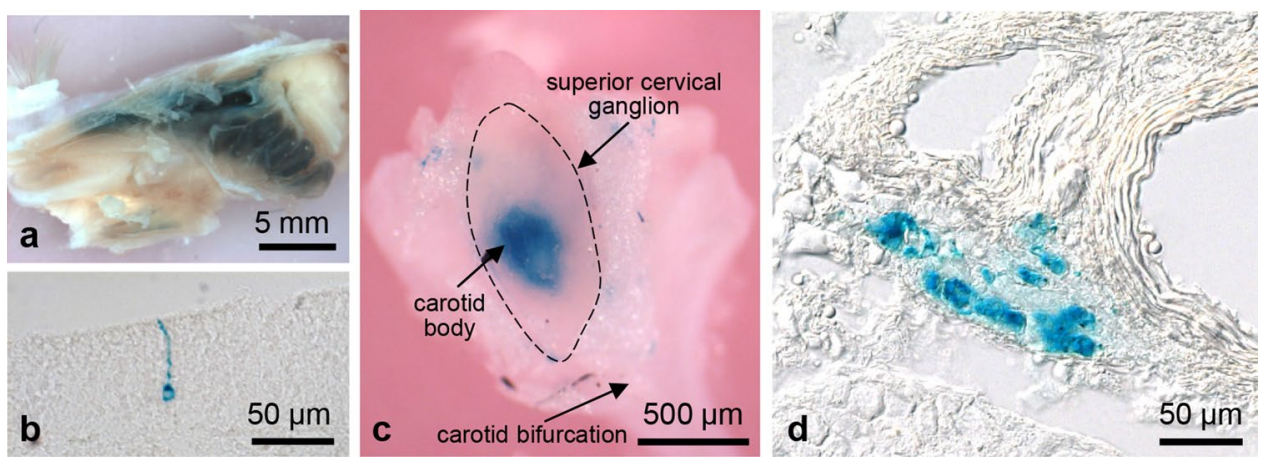

Fig. 11 X-gal staining of the olfactory epithelium and carotid body. $X$-gal staining of the nasal cavity with intensively stained olfactory epithelium (a). In the frozen section (b), a single positive olfactory neuron is shown. X-gal staining of the carotid body attached to the

glomus cells of the carotid body, sensory cells of the olfactory mucosa, enteroendocrine cells of the colon, and maturing sperm in the testis. These findings are consistent with data published by Conzelmann et al. (2000), Chang et al. (2015), Fleischer et al. (2015), Torres-Torrelo et al. (2018), and Flegel et al. (2016). However, we could not confirm expression of Olfr78 in retinal pigment cells and the choroid as described by Jovancevic et al. (2017) for the human eye. Contrary to the findings of Pluznick et al. (2013), we found no labelling of axons of the autonomic nervous system in heart, oesophagus, stomach, and other structures of the nervous system (DRGs, the femoral nerve, nerves supplying the extraocular muscles were $\mathrm{X}$-gal negative). Whereas expression of OR51E2 by cultured primary human airway smooth muscle cells has been demonstrated by RT-PCR (Natarajan et al. 2016), we obtained an Olfr78 RT-PCR product in just two of five lung samples and detected no X-gal staining in whole lungs or frozen sections of the organ. In all other organs in which we detected Olfr78 mRNA, the X-gal reaction product was localized in vascular smooth muscles cells, mostly of arterioles. We found no correlation between organs with X-gal-positive vessels and organ systems. In the female genital tract, for example, the ovary was negative and oviduct and uterus were positive. In the digestive tract, the esophagus was almost negative and the colon showed $\mathrm{X}$-gal-positive vessels.

The localization of Olfr78 in smooth muscle cells of the resistance vessels of the heart, diaphragm, skeletal muscle, and skin as well as in vascular smooth muscle cells of afferent arteriole of the juxtaglomerular apparatus of the kidney led Pluznick et al. (2013) to suspect that Olfr78 plays a role in blood pressure regulation. Subsequent experiments revealed that blood pressure regulation by SCFA, ligands of Olfr78, include another GPCR, Gpr41 (synonym: free fatty acid receptor 3). Using a luciferase-based reporter assay in which OR-ligand binding produces an increase in cAMP superior cervical ganglion (bordered by a dashed line) of the sympathetic trunk, which is located in the carotid bifurcation (c). The tissue was cleared for 10 days. Corresponding frozen section of the carotid body with intensively stained glomus cells (d)

that drives cAMP response element-dependent expression of luciferase, Pluznick et al. (2013) have demonstrated that Gpr41 is activated by fairly low concentrations of propionate $\left(\mathrm{EC}_{50}=\sim 11 \mu \mathrm{M}\right)$ whereas Olfr78 responds to high concentrations of propionate $\left(\mathrm{EC}_{50}=\sim 0.9 \mathrm{mM}\right)$. In mice, activation of Gpr41 by SCFAs lowers the blood pressure, whereas Olfr78 counters this response. Pluznick's group postulated that Olfr78 may act as a safety "brake" on Gpr41-mediated drops in blood pressure preventing an inappropriate level of hypotension, for example after a meal when blood concentration of SCFA is increased (Pluznick et al. 2013; Natarajan et al. 2016; Pluznick 2017). Such a mechanism seems particularly useful for the digestive tract to optimize the absorption of nutrients into the bloodstream through vasodilation without reducing blood pressure to critical levels.

Remarkably, we found Olfr78 expression especially in small blood vessels supplying striated-cardiac and skeletal-muscles widely distributed over the mouse body, independent of embryonic origin of the muscle fibres and their vascular and connective tissue elements. In craniofacial muscles, such as cheek muscles, the muscle fibres are derived from cranial paraxial and prechordal head mesoderm and the connective tissue with its vessels from the neural crest (Noden and Francis-West 2006; Ziermann et al. 2018). Myogenic cells of trunk muscles, such as intercostal muscle, derive from the epaxial lip and diaphragm and limb muscles from the hypaxial lip of the dermomyotome, with connective tissue coming from somites in the trunk and from the lateral plate mesoderm in the limbs (Nassari et al. 2017). Indicated by the X-gal product, Olfr78 expression was localized in circularly arranged smooth muscle cells. We identified these vessel segments as arterioles based on the vessel diameter, thickness of the muscle layer, and density of the smooth muscle cells. In agreement with Pluznick et al. (2013) we found, that only a subset of anti- $\alpha$-smooth muscle actinpositive cells of the muscle layer showed the X-gal product. 
Since each regional circulation of the body has unique requirements for blood supply and thus unique mechanisms for blood flow regulation, also the function/regulation of Olfr 78 may differ regionally (Reho et al. 2014). Contraction of the skeletal muscles results in marked dilation in all elements of the arteriolar tree, with the most pronounced dilation in the smallest arterioles (Joyner and Casey 2015). A number of vasodilators are formed in exercising muscles and it appears that none of them operate independently or are essential for reaching adequate blood flow during exercise. This redundancy is an important concept to secure exercise hyperaemia for adequate oxygen supply (Hellsten et al. 2012). Bradykinin is a potent vasodilator that acts through bradykinin receptor 2 (B2R), which is constitutively expressed by endothelial cells. Ligand binding causes the release of nitric oxide and endothelium-derived hyperpolarizing factor resulting in relaxation of smooth muscles cells. Recently, bradykinin was identified as a novel agonist of OR51E2 (Abaffy et al. 2018). Using a luciferase-based reporter assay Abaffy et al. estimated an $\mathrm{EC}_{50}$ value of $1.30^{-9} \mathrm{M}(=1.3 \mathrm{nM})$ for bradykinin. The median bradykinin concentration in plasma samples from healthy volunteers is $0.7 \mathrm{nmol} / 1$ (range 0.5-1.1 nmol/l) (Lindström et al. 2019). Already in 1990, Stebbins et al. (1990) described that in cats electrical stimulation of the triceps surae muscles causes a distinct increase in bradykinin concentration in the venous effluent of the muscle. Langberg et al. (2002) reported an interstitial concentration of bradykinin in the human medial gastrocnemius muscle of $23.1 \mathrm{nmol} / \mathrm{l}$, which raises to $110.5 \mathrm{nmol} / \mathrm{l}$ in response to exercise. In principle, these bradykinin concentrations would be sufficient to activate Olfr78 expressed by vascular smooth muscle cells of the skeletal microvasculature and probably contribute to exercise induced hyperaemia. The high expression of Olfr78 in the smooth muscle cells of the femoral artery may also participate in regulation of the blood flow to the muscles of the limb.

If Olfr78 is to be used as a target for the development of new therapies of hypertension or of prostate cancer, the widespread expression of the receptor in small blood vessels especially of striated muscles must be kept in mind.

Author contributions JS provided the transgenic mouse line MOL2.3IGITL (designation in our animal facility and in the permission: CD1;129-Olfr $78^{\text {tmljgst }}$ ). RP and PM carried out tissue collection and fixation. They performed whole-mount X-gal staining, prepared frozen sections, and used them for immunohistochemistry. PM carried out the RT-PCR analysis. RP designed and coordinated the study and drafted the manuscript. All authors have read and approved the final manuscript.
Funding Open Access funding enabled and organized by Projekt DEAL. This work was supported by the DFG (SFB-TR84, project A06 to WK).

Data availability The data that support the findings of this study are available from the corresponding author upon reasonable request.

\section{Declarations}

Conflict of interest The authors declared no potential conflicts of interest with respect to the research, authorship, and/or publication of this article.

Ethics approval All experiments were performed according to the national and international guidelines and with approval of local authorities (Animal Welfare Officer at the University of Giessen) and the Federal Authorities for Animal Research of the Regierungspräsidium Giessen (Hessen, Germany), registration number (\# 614_M). All methods are reported in accordance with ARRIVE guidelines.

Open Access This article is licensed under a Creative Commons Attribution 4.0 International License, which permits use, sharing, adaptation, distribution and reproduction in any medium or format, as long as you give appropriate credit to the original author(s) and the source, provide a link to the Creative Commons licence, and indicate if changes were made. The images or other third party material in this article are included in the article's Creative Commons licence, unless indicated otherwise in a credit line to the material. If material is not included in the article's Creative Commons licence and your intended use is not permitted by statutory regulation or exceeds the permitted use, you will need to obtain permission directly from the copyright holder. To view a copy of this licence, visit http://creativecommons.org/licenses/by/4.0/.

\section{References}

Abaffy T, Bain JR, Muehlbauer MJ, Spasojevic I, Lodha S, Bruguera E, O'Neal SK, Kim SY, Matsunami H (2018) A testosterone metabolite 19-hydroxyandrostenedione induces neuroendocrine trans-differentiation of prostate cancer cells via an ectopic olfactory receptor. Front Oncol 8:162. https://doi.org/10.3389/fonc. 2018.00162

An SS, Liggett SB (2018) Taste and smell GPCRs in the lung: evidence for a previously unrecognized widespread chemosensory system. Cell Signal 41:82-88. https://doi.org/10.1016/j.cellsig. 2017.02.002

Chang AJ, Ortega FE, Riegler J, Madison DV, Krasnow MA (2015) Oxygen regulation of breathing through an olfactory receptor activated by lactate. Nature 527(7577):240-244. https://doi.org/ 10.1038 /nature 15721

Conzelmann S, Levai O, Bode B, Eisel U, Raming K, Breer H, Strotmann J (2000) A novel brain receptor is expressed in a distinct population of olfactory sensory neurons. Eur J Neurosci 12(11):3926-3934. https://doi.org/10.1046/j.1460-9568.2000. 00286.x

Flegel C, Vogel F, Hofreuter A, Schreiner BS, Osthold S, Veitinger S, Becker C, Brockmeyer NH, Muschol M, Wennemuth G, Altmüller J, Hatt H, Gisselmann G (2016) Characterization of the olfactory receptors expressed in human spermatozoa. Front Mol Biosci 2:73. https://doi.org/10.3389/fmolb.2015.00073

Fleischer J, Bumbalo R, Bautze V, Strotmann J, Breer H (2015) Expression of odorant receptor Olfr78 in enteroendocrine cells of the 
colon. Cell Tissue Res 361(3):697-710. https://doi.org/10.1007/ s00441-015-2165-0

Heifetz A, Schertler GF, Seifert R, Tate CG, Sexton PM, Gurevich VV, Fourmy D, Cherezov V, Marshall FH, Storer RI, Moraes I, Tikhonova IG, Tautermann CS, Hunt P, Ceska T, Hodgson S, Bodkin MJ, Singh S, Law RJ, Biggin PC (2015) GPCR structure, function, drug discovery and crystallography: report from academiaindustry international conference (UK Royal Society) Chicheley Hall, 1-2 September 2014. Naunyn Schmiedebergs Arch Pharmacol 388(8):883-903. https://doi.org/10.1007/s00210-015-1111-8

Hellsten Y, Nyberg M, Jensen LG, Mortensen SP (2012) Vasodilator interactions in skeletal muscle blood flow regulation. J Physiol 590(24):6297-6305. https://doi.org/10.1113/jphysiol.2012. 240762

Jovancevic N, Khalfaoui S, Weinrich M, Weidinger D, Simon A, Kalbe B, Kernt M, Kampik A, Gisselmann G, Gelis L, Hatt H (2017) Odorant receptor 51E2 agonist $\beta$-ionone regulates RPE cell migration and proliferation. Front Physiol 8:888. https://doi.org/10. 3389/fphys.2017.00888

Joyner MJ, Casey DP (2015) Regulation of increased blood flow (hyperemia) to muscles during exercise: a hierarchy of competing physiological needs. Physiol Rev 95(2):549-601. https://doi. org/10.1152/physrev.00035.2013

Langberg H, Bjørn C, Boushel R, Hellsten Y, Kjaer M (2002) Exerciseinduced increase in interstitial bradykinin and adenosine concentrations in skeletal muscle and peritendinous tissue in humans. J Physiol 542(3):977-983. https://doi.org/10.1113/jphysiol.2002. 018077

Lindström M, Valkonen M, Tohmola N, Renkonen R, Strandin T, Vaheri A, Itkonen O (2019) Plasma bradykinin concentrations during septic shock determined by a novel LC-MS/MS assay. Clin Chim Acta 493:20-24. https://doi.org/10.1016/j.cca.2019.02.023

Maßberg D, Hatt H (2018) Human olfactory receptors: novel cellular functions outside of the nose. Physiol Rev 98(3):1739-1763. https://doi.org/10.1152/physrev.00013.2017

Nassari S, Duprez D, Fournier-Thibault C (2017) Non-myogenic contribution to muscle development and homeostasis: the role of connective tissues. Front Cell Dev Biol 5:22. https://doi.org/10.3389/ fcell.2017.00022

Natarajan N, Hori D, Flavahan S, Steppan J, Flavahan NA, Berkowitz DE, Pluznick JL (2016) Microbial short chain fatty acid metabolites lower blood pressure via endothelial G protein-coupled receptor 41. Physiol Genomics 48(11):826-834. https://doi.org/ 10.1152/physiolgenomics.00089.2016

Noden DM, Francis-West P (2006) The differentiation and morphogenesis of craniofacial muscles. Dev Dyn 235(5):1194-1218. https:// doi.org/10.1002/dvdy.20697

Pluznick JL (2017) Microbial short-chain fatty acids and blood pressure regulation. Curr Hypertens Rep 19(4):25. https://doi.org/10.1007/ s11906-017-0722-5

Pluznick JL, Protzko RJ, Gevorgyan H, Peterlin Z, Sipos A, Han J, Brunet I, Wan LX, Rey F, Wang T, Firestein SJ, Yanagisawa M, Gordon JI, Eichmann A, Peti-Peterdi J, Caplan MJ (2013)
Olfactory receptor responding to gut microbiota-derived signals plays a role in renin secretion and blood pressure regulation. Proc Natl Acad Sci USA 110(11):4410-4415. https://doi.org/10.1073/ pnas. 1215927110

Reho JJ, Zheng X, Fisher SA (2014) Smooth muscle contractile diversity in the control of regional circulations. Am J Physiol Heart Circ Physiol 306(2):H163-H172. https://doi.org/10.1152/ajphe art.00493.2013

Sriram K, Insel PA (2018) G Protein-coupled receptors as targets for approved drugs: how many targets and how many drugs? Mol Pharmacol 93(4):251-258. https://doi.org/10.1124/mol.117. 111062

Stebbins CL, Carretero OA, Mindroiu T, Longhurst JC (1990) Bradykinin release from contracting skeletal muscle of the cat. J Appl Physiol 69(4):1225-1230. https://doi.org/10.1152/jappl.1990. 69.4.1225

Torres-Torrelo H, Ortega-Sáenz P, Macías D, Omura M, Zhou T, Matsunami H, Johnson RS, Mombaerts P, López-Barneo J (2018) The role of Olfr78 in the breathing circuit of mice. Nature 561(7724):E33-E40. https://doi.org/10.1038/s41586-018-0545-9

Treweek JB, Chan KY, Flytzanis NC, Yang B, Deverman BE, Greenbaum A, Lignell A, Xiao C, Cai L, Ladinsky MS, Bjorkman PJ, Fowlkes CC, Gradinaru V (2015) Whole-body tissue stabilization and selective extractions via tissue-hydrogel hybrids for highresolution intact circuit mapping and phenotyping. Nat Protoc 10(11):1860-1896. https://doi.org/10.1038/nprot.2015.122

Weiss DJ, Liggitt D, Clark JG (1999) Histochemical discrimination of endogenous mammalian beta-galactosidase activity from that resulting from lac-Z gene expression. Histochem J 31(4):231-236. https://doi.org/10.1023/a:1003642025421

Weng J, Wang J, Cai Y, Stafford LJ, Mitchell D, Ittmann M, Liu M (2005) Increased expression of prostate-specific G-proteincoupled receptor in human prostate intraepithelial neoplasia and prostate cancers. Int J Cancer 113(5):811-818. https://doi.org/10. 1002/ijc. 20635

Xu LL, Stackhouse BG, Florence K, Zhang W, Shanmugam N, Sesterhenn IA, Zou Z, Srikantan V, Augustus M, Roschke V, Carter K, McLeod DG, Moul JW, Soppett D, Srivastava S (2000) PSGR, a novel prostate-specific gene with homology to a $G$ protein-coupled receptor, is overexpressed in prostate cancer. Cancer Res 60(23):6568-6572

Zhou T, Chien MS, Kaleem S, Matsunami H (2016) Single cell transcriptome analysis of mouse carotid body glomus cells. J Physiol 594(15):4225-4251. https://doi.org/10.1113/JP271936

Ziermann JM, Diogo R, Noden DM (2018) Neural crest and the patterning of vertebrate craniofacial muscles. Genesis 56(67):e23097. https://doi.org/10.1002/dvg.23097

Publisher's Note Springer Nature remains neutral with regard to jurisdictional claims in published maps and institutional affiliations. 